University for Business and Technology in Kosovo

UBT Knowledge Center

UBT International Conference

2015 UBT International Conference

Nov 7th, 9:00 AM - 5:00 PM

\title{
Understanding Residential Electricity Consumption Considering Energy Efficiency Policies and The Impact On the Electricity System
}

\author{
Meryem Nur Morgül Tumbaz \\ Sakarya University, meryemtumbaz@sakarya.edu.tr \\ Hatice Tekiner Muğlkoç \\ Istanbul Şehir University, haticetekiner@sehir.edu.tr
}

Follow this and additional works at: https://knowledgecenter.ubt-uni.net/conference

Part of the Engineering Commons

\section{Recommended Citation}

Tumbaz, Meryem Nur Morgül and Muğlkoç, Hatice Tekiner, "Understanding Residential Electricity Consumption Considering Energy Efficiency Policies and The Impact On the Electricity System" (2015). UBT International Conference. 49.

https://knowledgecenter.ubt-uni.net/conference/2015/all-events/49

This Event is brought to you for free and open access by the Publication and Journals at UBT Knowledge Center. It has been accepted for inclusion in UBT International Conference by an authorized administrator of UBT Knowledge Center. For more information, please contact knowledge.center@ubt-uni.net. 


\title{
Understanding Residential Electricity Consumption Considering Energy Efficiency Policies and The Impact On the Electricity System
}

\author{
Meryem Nur Morgül Tumbaz ${ }^{1}$, Hatice Tekiner Muğlkoç² \\ Department of Industrial Engineering, Turkey \\ ${ }^{1}$ Sakarya University, \\ ${ }^{2}$ Istanbul Şehir University \\ meryemtumbaz@sakarya.edu.tr¹,haticetekiner@sehir.edu.tr
}

\begin{abstract}
Electricity consumption increases substantially over the years where residential use significantly contributes to the overall consumption. The growth in the population and variety of home appliances together with increasing comfort levels of the people results in higher levels of residential electricity use. In fact, nearly one fourth of Turkey's total electricity consumption is due to the domestic use. To achieve global sustainability targets and reduce the overall electricity use, focusing on the domestic consumption is crucial. In this research, the energy consumptions patterns of households are determined to identify the potential electricity savings existing in the residential sector. Moreover, specific policy recommendations which can promote the behavioral change are driven by measuring the responsiveness of people to different measures and the combinations of these measures such as information, feedback, rewards, and social influences.

A survey was conducted to determine the patterns and the responsiveness of the residential customers. The results obtained from the survey are used to depict a general view of Turkish households towards electricity consumption behaviors and their energy efficiency attitudes. Responses indicate there should be more regulations and improvements in energy policy. An electricity allocation problem is solved in order to see possible impacts of behavioral change measures on the network. Scenarios are defined for each policy and allocation problem is solved to see the possible generation cost reduction. Also, gas emissions for each scenario is recorded to understand the possible effects of policies on the environment. Results show that behavioral change studies seem to be well worth to study. In order to reach residential efficiency, possible policy alternatives are suggested for Turkish households.
\end{abstract}

Keywords: Energy efficiency, residential electricity consumption, consumer behaviors, behavioral change, policy implementation, impacts on the electricity network

\section{Introduction}

Residential electricity consumption accounts for $23 \%$ of total electricity con- sumption in Turkey [1]. Moreover, the number of residential electricity users is more than $80 \%$ of total electricity consumers and residential consumers con- tribute to the largest peak demand [2]. In addition to Turkey's increasing residen- tial energy demand, the share of standby consumption is also worth considering, $3 \%$ of total electricity goes for unused consumption [3]. The use rate of electrical appliances is high, especially the rate of electric teapots and electric heaters are as much as essential products, such as a fridge and washing machine [4]. Studies towards understanding the customers have three elements: one for the consumers and one for electricity providers, and one for countries. Consumers do not know the amount of energy they consume when they use. Some users may think that they use energy efficiently and they do not consume much energy. However, in general, there is a difference between consumer intention and actual behaviors. This gap may be a tool for behavioral change. Once they are convinced of their consumption as inefficient and not compatible with their intention, it is easy for them to adopt efficient use manners. Using energy efficiently will reduce the consumption and decrease the electricity bill of house- holds. More importantly, in the long term, society will certainly gain from this. Secondly, meeting demand is a 
primary target of electricity providers. Companies that have more accurate customer profiles in their hands will estimate true demand. When consumer free choice becomes common, providers will compete to attract or keep their customers. In such a rivalry, companies who know their consumers, understand their concerns, and even guide them regarding their electricity consumption will succeed. Last but not least, countries will also gain from understanding consumers. In order to reach a sustainable environment, reducing energy consumption and gas emissions are crucial. For countries whom energy demand is dependent on imports, managing energy demand is much more essential. Moreover, making appropriate policies for consumer groups will avoid wasting time and budget for the country. These are all possible through a better understanding of consumers, and it requires a precise study on the subject.

\section{Household Survey}

In order to meet the need for research into current practices of households and their intention towards different policies about energy efficiency, surveying has been chosen. The questions were designed to allow easier understanding of how residential users respond to the issues such as pricing, willingness to change their behavior, the kind of additional information they thought it would be effective to reduce their consumption, and the types of energy policies they would be willing to engage with. Questionnaire comprised of 50 questions, which took a maximum of fifteen minutes to complete. The survey was accessible to the public through the website in Turkish between July 2013 to August 2014. The questions were targeted at end users and reached 670 people. However, the number of complete responses was 526.

\subsection{General findings of the survey}

The results of the survey are presented in this section. Results regarding the peak demand behavior, willingness to shift this time use to less peak hours, and standby consumption are summarized. The motivation level of consumers for behavioral change and households' response to policies are given. Energy labeling: In a survey completed by 526 people, $68 \%$ of consumers said they are aware of energy labeling. According to the results, nearly all of these consumers know the energy class of appliances in their house and they take into account the energy class when purchasing anew product. Although they are familiar with energy class, consumers do not favor of buying energy efficient products due to their expensiveness. Furthermore, knowing energy class and having more efficient products in their houses do not mean consuming energy efficiently. There are no differences on the percentage of efficient consumption behaviors among consumers who consider energy labels when buying a new product and who do not. Efficient consumption behaviors are defined as turning off unnecessary lights, running the machines at full capacity, preferring to boil water on a gas furnace, and so on.

Peak hour usage: Electrical teapot or coffee machine emerged as the appliance which had the highest number of respondents indicating they always use it between 5 to 10 o'clock in the evening, followed by dishwasher. Despite their attitudes towards shifting washing machine and dishwasher use participants are not in favor of changing the use of kettle/tea or coffee machines. This can be explained by the traditional habit of Turkish households.

Standby consumption: Consumers defined themselves as conscious about standby consumption. However, Turkey's standby consumption is high and keeps increasing [3].Forgetting to unplug is most common answer to the question of why to leave computers, TVs, or other appliances standby.

Kettle use: Although consumers defined themselves as conscious regarding some behaviors or attitudes towards energy efficiency, their kettle use is on the opposite of this scheme. Even consumers have more efficient consumption habits in their home are not conscious of the impact of using an electric teapot, or kettles. End-users can be thought as more resistant to change their kettle use habits.

Smart meters: $70 \%$ of participants stated they were aware of smart meters, but only half of them used at homes. When consumers are examined about their electricity use during peak hours and possession of smart meters, the results are confusing. The percentage of using appliances from 5 
to 10 o'clock is nearly the same among users who have smart meters and who do not. This means consumers are not well informed about the practice and purpose of smart meters. More informative measures should be the primary target.

Familiarity of efficiency projects: Participants were asked about the ef- ficiency projects conducted by Ministry of Energy and Natural Resources, and 79\% of them said that they have never heard of these projects. Projects have being announced on TV as public service ads for a long time. However, familiarity with them was very low and limited. Timing could be altered or format should be redesigned.

Motivators for behavioral change: Participant were also asked what mo- tivator would be most effective to change their behavior regarding electricity consumption during peak periods and to avoid standby consumption. Monetary drivers such as "more expensive electricity at that time", "knowing the contribution of standby to the household budget" seem to be more effective.

Measures: Five measures successful in changing behavior were chosen to appear on a list in the survey. First of all, 23\% of participants chose informative measures as more effective for behavioral change. People are interested in learning methods of efficient use of electricity mostly via TV and the Internet. Public service ads and then documentaries are the kinds of formats they would like to see on TV. One fourth of participants have chosen feedback as their preferred behavioral change measure. Consumers are open to a new format of billing. They are willing to see more informative data on their bill including the environmental impact of their consumption, the comparison with last month's consumption and so on. Providing access to their consumption at any time also impacts consumption and should be an alternative to keep consumers more often informed of their energy consumption. At a rate of $37.1 \%$, reward is the most common method to incentivize for behavioral change. Unsurprisingly, people have opted for monetary rewards in return for using energy efficiently. In addition to a reward, disincentives had also been listed in the survey and disincentives were chosen by $9.1 \%$ of households. It would not be wrong to consider disincentives as the opposite of rewards. For this reason, monetary disincentives could be a tool to attain energy efficient behaviors. According to Prospect Theory people will react to a loss rather than a gain. Therefore, we would expect to see disincentives at a higher rate among participants [5]. However, it is not also surprising for households to opt for rewards. The Rational Choice Theory say s people are always in favor of gaining benefits [6], [7], [8]. Last, only 5\% of respondents choose social activities as a behavioral change measure. People thin activities taking place at schools would be more enjoyable and more informative. Probably households with children are willing to partici- pate in such activities for the purpose of being a good model for their children and leaving them a better society.

Policy alternatives: Nowadays Turkish audience is familiar with some col- orful messages on TV played after 21:00 o'clock reminding kids of going to bed. In the survey, people were asked whether they found similar quick messages on TV effective or not for changing their behavior. These messages have been thought of as "don't leave your TV standby", "Please turn off unnecessary lights". $74.3 \%$ of participants found these kinds of messages help ful to get sustainable behav- iors into their homes. People were also asked whether they thought stickers or magnets on the appliances reminding them of using energy efficiently could be helpful. Giving advice such as "run me after 22:00", "run me at full capacity", "choose eco program" etc. were found effective with $62.6 \%$. It is also seen in the survey $74.1 \%$ of households would reduce or shift their electricity consumption when they were warned about high demand periods. This shows consumers are willing to change their behavior to reduce demand.

\section{Application on Turkis h Electricity Network}

The mathematical formulation of the model is presented. This model is a very simple model disregarding transmission lines, energy losses, and location of the generation. The target here is to represent the effects of behavioral change studies on electricity demand an the environment. Sets:

I : Available electricity generation sources.

G: Total number of days chosen.

$\mathrm{N}$ : Total number of hours in each day. 
$\mathrm{H}_{\mathrm{dn}}$ : set of hours where demand is high and the policy applied might switch the demand from these hours.

$\mathrm{L}_{\mathrm{dn}}$ : set of hours where demand is low and the policy applied might switch the demand to these hours.

$\mathrm{O}_{\mathrm{dn}}$ : set of hours where switching scenarios have no impacts

D: set of dispatchable units which can provide a continuous output on demand, i.e. fossil fuels, nuclear plants.

N D: set of non-dispatchable units such as solar and wind turbines. These units are periodic and uncontrollable.

Decision variables:

$\mathrm{x}_{\mathrm{idn}}$ : the amount of electricity generation from unit $\mathrm{i}$ on day $\mathrm{d}$ and hour $\mathrm{n}$.

Parameters:

$\mathrm{c}_{\mathrm{i}}$ : generation cost of unit $\mathrm{i}(\$ / \mathrm{MWh})$.

$\mathrm{K}_{\mathrm{i}}$ : installed capacity of unit $\mathrm{i}(\mathrm{MW})$.

$\mathrm{f}_{\mathrm{i}}$ : capacity factor of unit $\mathrm{i}$.

$\mathrm{w}_{\mathrm{dn}}$ : adjustment factor of day $\mathrm{d}$ and hour $\mathrm{n}$. This means the number of days represented by each selected day and hour. For example, if the problem is solved with a single day chosen, the adjustment factor of this day will be 365 .

$\mathrm{D}_{\mathrm{dn}}$ : electricity demand on day d and hour $\mathrm{n}(\mathrm{MWh})$.

$\mathrm{e}_{\mathrm{dn}}$ : possible demand reduction due to efficient use of electricity on day $\mathrm{d}$ and hour $\mathrm{n}$. It is calculated by multiplying the demand and the efficiency rate EFdn. EFdn is defined as efficiency rate of a scenario that leads to decrease in demand.

$$
\mathrm{e}_{\mathrm{dn}}=\mathrm{D}_{\mathrm{dn}} \cdot \mathrm{EF}_{\mathrm{dn}} \quad \forall \mathrm{d}, \mathrm{n}
$$

$\mathrm{S}_{\mathrm{dn}}$ : reduction in demand due to the shifted amount of electricity on day $\mathrm{d}$, hour $\mathrm{n}$. It is calculated by multiplying the demand and SFdn, which is the ratio of electricity switched from time high hours of day $d$.

$$
\mathrm{S}_{\mathrm{dn}}=\mathrm{D}_{\mathrm{dn}} \cdot \mathrm{SF}_{\mathrm{dn}} \quad \forall \mathrm{d}, \mathrm{n} \in \mathrm{Hdn}
$$

$\mathrm{t}_{\mathrm{dn}}$ : increase in demand due to the shifted amount of electricity on day d, hour $\mathrm{n}$. It is calculated by multiplying the sum of switching ratio from times Hdn and STdn, which is the ratio of electricity switched to time low hours of day d.

$$
t_{d n}=\left(\sum_{n} S F_{d n}\right) S T_{d n} \quad \forall d, n \in L_{d n}
$$

The problem is solved given a single-objective function problem. The objec- tive function and the model are as follows. 


$$
\begin{aligned}
& \min z=\sum_{i}^{I} \sum_{d}^{G} \sum_{n}^{N} x_{i d n} \cdot c_{i} \cdot w_{d n} \\
& \text { s.t. } \\
& \qquad \sum_{i}^{I} x_{i d n} \geq D_{d n}-e_{d n} \quad \forall d, n \in O_{d n} \\
& \qquad \sum_{i}^{I} x_{i d n} \geq D_{d n}-e_{d n}-s_{d n} \quad \forall d, n \in S_{d n} \\
& \sum_{i}^{I} x_{i d n} \geq D_{d n}-e_{d n}+t_{d n} \quad \forall d, n \in T_{d n} \\
& \sum_{i}^{I} x_{i d n} \leq K_{i} \cdot f_{i} \quad \forall i, d, n \in D \\
& \sum_{i}^{I} x_{i d n}=K_{i} \cdot f_{i} \quad \forall i, d, n \in N D
\end{aligned}
$$

Equations 4 to 6 pertain to demand constraints. These constraints reflects the changes with respect to the impact of policies on the electricity use. If the policy includes efficient use of electricity, which will lead reduction in demand, demand is reduced by edn (Equation 4). If the policy includes shifting for some hours, then demand in the corresponding hours will be decreased as in Equation 5.

This shift will increase the demand in the hours where policy is organized to shift the demand to as in Equation 6.

Equation 7 and 8 are related to capacity constraints. If the demand is met by dispactchable units, the amount of electricity produced will be less than or equal to the capacity (Equation 7). However, if the electricity comes from nondispatch-able units such as wind or solar energy, generated amount of electricity will be equal to the multiplication of the capacity of the nondispatchable unit (Ki ) and its capacity factor fi. The one-year consumption of Turkey has been investigated in detail and he most representative and appropriate days to the total consumption data are selected for the model. Since peak hours occur at different periods of the day, examined days are divided into three: weekday, Saturday, and Sunday. 6 hours for high demand (Hdn ) and 6 hours for low demand (Ldn ) occurs has been noted for the model. The rest 12 hours in each day are listed in the set of Odn . The access of daily demand data is restricted, and it is available only from June 2013 to today. In accordance with the consumption data and peak hour period, most appropriate months of the year has been chosen to represent the first five months of 2013. In total, there are 21 days in the mathematical model. Table 1 shows selected dates with maximum demand and the number of days (wdn ) they represent. 
Table 1. Adjustment factor and demand data of the examined days in the model

\begin{tabular}{|c|c|c|c|c|c|c|c|c|c|}
\hline Month & Weekday & $w_{d u}$ & $D=\operatorname{mand}(\mathrm{M}$ J & Saturday & $w_{d x}$ & Demand (MANA) & Sunday & $w_{d u}$ & Demand(MAX) \\
\hline June & 27.06 & 20 & 723181 & 29.06 & y & 716231 & 30.06 & 5 & 634760 \\
\hline July & 11.07 & 23 & 768880 & 13.07 & 4 & 738304 & 14.07 & 4 & 667179 \\
\hline August & 29.08 & 22 & 772150 & 03.08 & 5 & 729777 & 04.08 & 4 & 673163 \\
\hline September & 03.09 & 21 & 738240 & 14.09 & 4 & 692108 & 01.09 & 5 & 627527 \\
\hline October & 08.10 & 109 & 686383 & 05.10 & 21 & 659473 & 27.10 & 21 & 608318 \\
\hline November & 29.11 & 21 & 715829 & 30.11 & 5 & 689871 & 17.11 & 4 & 603641 \\
\hline December & 19.12 & 45 & 762976 & 21.12 & 4 & 727342 & 22.12 & 9 & 661298 \\
\hline
\end{tabular}

Table 2. Generation units by source and their related characteristics

\begin{tabular}{|c|c|c|c|c|c|c|}
\hline Units (1) & Capacity $\left(\mathrm{K}_{\mathrm{i}}\right)$ & Factor $(\mathrm{f})$ & Unit Cost $\left(c_{i}\right)$ & $\mathrm{CO}_{2}$ & $\mathrm{SO}_{2}$ & $\mathrm{NO}_{\mathrm{x}}$ \\
\hline (source) & $(M W)$ & & (\$/SWLh) & (16s\&u(h) & (16s\&Whb) & (16s\&Wha) \\
\hline Liquid Fuels & 694 & 0.77 & 223.6 & 243.04 & 2.25 & 0.88 \\
\hline Hard coal//1gnite & 8515 & 0.85 & 115.9 & 734.21 & 2.51 & 1.47 \\
\hline Imported coal & उपार & 0.85 & 92.6 & 779.53 & 2.85 & 1.56 \\
\hline Natural gas & 20252 & 0.85 & 128.4 & 398.91 & 0.31 & 0.25 \\
\hline Waste energy & 224 & 0.85 & 102.6 & 726.33 & J & 0.47 \\
\hline Geothermal & $3 \pi$ & 0.75 & 47.9 & 154.4 & 0 & 0 \\
\hline Hydraulic & 22289 & 0.50 & 84.5 & J & 0 & J \\
\hline Wind & $2760^{\circ}$ & 0.30 & 80.3 & 0 & 0 & 0 \\
\hline
\end{tabular}

The network has 8 types of generation units. These units are listed in Ta- ble 2 with the corresponding capacity [9], factor [10], and unit cost data [11]. Emission rates are adopted from several resources [12], [13], [14], [15]. Levelized cost of electricity includes capital cost of the plant, fuel cost, operational and maintenance cost. These ty pes of costs are thought as a better option to avoid some drawbacks of our mathematical model. In our model, electricity generation units are accepted as wholly available for each region. However, in reality, some units are installed only in certain regions, such as wind turbines and hydraulic plants. If the fuel prices were considered only, there would not be any cost for these two units.

The created scenarios are applied to the model and results are obtained. The model also considers the case of having no policy applied in order to see change in the cost, the demand, and the emissions. A sample of created scenarios are listed below.

1. Efficient use messages on TV leads to $10 \%$ reduction in residential demand with $74.3 \%$ willingness of households

2. Magnets or stickers reminding of efficient use of electricity leads to $10 \%$ reduction in residential demand with $62.6 \%$ willingness of households

3. Replacing 4 million old fridges with efficient ones

4. During school term (from October to May), organizing social events at school and reducing electricity consumption in residential areas

5. Replacing kettles with $35 \%$ more efficient ones

6. Shifting all of dishwasher use between 17:00 and 22:00 to late hours

7. Shifting all of the iron use between $17: 00$ and 22:00 to the early hours in the morning

Solutions for the mathematical model is given in Table 3 . When there is no policy adopted the cost becomes $\$ 26.5$ billion and the demand equals to $2.58 \times 10^{8} \mathrm{MWh}$. $41 \%$ of electricity is generated from non-fossil fuels in this case. Although it is very little, all of the created scenarios lead to a decrease in demand and cost, and result in higher rate of renewable energy use. This should emphasize the importance of encouraging using behavioral change policies in a large scale to meet sustainability targets. Figure 1 shows the reduction rate of scenarios both in the cost and the demand. 
International Conference on Energy Efficiency Engineering, Nov 2015

Table 3. Cost, non-fossil source use, and emission rates for each scenario

\begin{tabular}{c|c|c|c|c|c}
\hline Cases & Cost & non-fossiluse & $\mathrm{CO}_{2}$ & $\mathrm{SO}_{2}$ & $\mathrm{NO}_{\mathrm{x}}$ \\
\hline & (billons of \$) & $\%$ & (lbs) & $(\mathrm{lbs})$ & $(\mathrm{Ibs})$ \\
\hline 0 & 26.516 & 41.47 & $9.335 .10^{\circ}$ & $5.36 .10^{\circ}$ & $1.53 .10^{\circ}$ \\
1 & 25.903 & 42.26 & $9.139 .10^{10}$ & $5.34 .10^{8}$ & $1.52 .10^{8}$ \\
2 & 26.000 & 42.13 & $9.170 .10^{10}$ & $5.34 .10^{8}$ & $1.52 .10^{8}$ \\
3 & 26.256 & 41.80 & $9.252 .10^{10}$ & $5.35 .10^{8}$ & $1.53 .10^{8}$ \\
4 & 25.989 & 42.15 & $9.163 .10^{10}$ & $5.34 .10^{8}$ & $1.52 .10^{8}$ \\
5 & 26.503 & 41.49 & $9.331 .10^{10}$ & $5.36 .10^{8}$ & $1.53 .10^{8}$ \\
6 & 26.514 & 41.47 & $9.342 .10^{10}$ & $5.37 .10^{8}$ & $1.54 .10^{8}$ \\
7 & 26.437 & 41.57 & $9.312 .10^{10}$ & $5.36 .10^{8}$ & $1.53 .10^{8}$
\end{tabular}

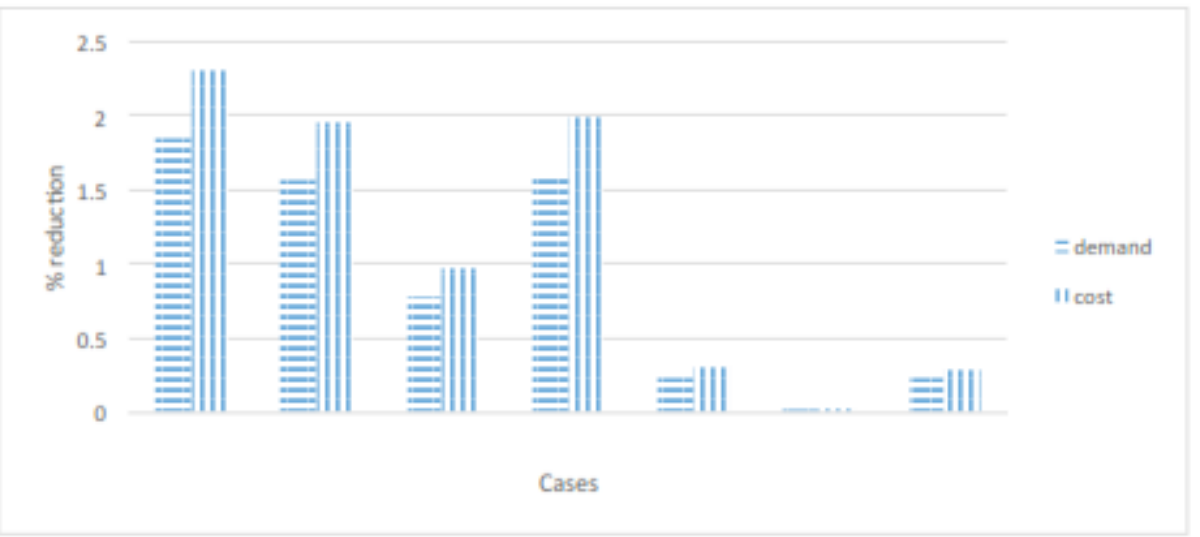

Fig. 1. Reduction in cost and demand from each scenario (\%)

As a summary of case results, these can be concluded:

- Messages on TV or magnets and stickers seem to an efficient way of promot-ing behavioral change. These types of new policies should be considered.

- Avoiding standby consumption and giving incentives to replace old fridges with more efficient ones will bring a noticeable change to the network.

- Social influences can also be suggested to promote efficient use of electricity among Turkish households. Scenario 4, which proposes to follow efficiency measures during school term, has the higher reduction ratio among similar cases.

- Having tea after dinner is a traditional habit of Turkish households and it cannot be avoided. Survey results show that the ownership and the use rate of electrical teapots are high, and households were unwilling to avoid their use at peak hours. Therefore, policy makers should examine the problem carefully. Making manufacturers to develop higher efficiency tea machines can be one option, or severe policies can be developed to prevent using electricity to boil water or making tea.

- Although there is always a reduction in the cost and the demand, Scenario 6 ends up with higher emission rates. This increase can be explained by using higher amount of coal in the generation process. Considering environmen- tal impact of different scenarios is noteworthy to reach sustainability in the framework of global regulations. Scenario 7 has a visible impact on the network. Shifting iron use from late hours to early morning will be effective to deal with the peak demand. 


\section{References}

1. Yıllar itibariyle Türkiye net elektrik tu"ketiminin sektorlere gore da“gllımı, http: //www.oib.gov.tr/tedas/tedas.htm (2010)

2. Elektrik dagitım , sirketleri abone sayılarının sektorlere gore da gilımı, http://www. oib.gov.tr/tedas/tedas.htm (2010)

3. International Energy Agency: Things That Go Blip in the Night: Standby Power and How to Limit It, France (2001)

4. Enerji Hanım Anketi Degerlendirme Sonu,cları, http://www.enerjihanim.com/tr/ anketsonucu/enerji-hanim-anket-degerlendirme-sonuclari/3 (2012)

5. Nair, G., Gustavsson, L., Mahapatra, K.: Factors influencing energy efficiency in investments in existing Swedish residential buildings, Energy Policy, 38, 2956-2963 (2010)

6. Martiskainen, M.: Affecting consumer behaviour on energy demand, Sussex Energy Group, University of Sussex (2007)

7. Abreu, J.: Understanding Consumer behavior for energy conservation: a fremework for research, Sustainable Energy System, MIT Portugal (2008)

8. Jackson, T.: Motivating Sustainable Consumption: A review of evidence on con- sumer behavior and behavioral change, Sustainable Development Research Network, University of Sussex (2005)

9. Türkiye Elektrik Enerjisi Kurulu, s ve Yakıt Cinsine G”ore Kurulu Güc, www.teias. gov.tr/y ukdagitim/kuruluguc.xls

10. Ozcan, M.: Turkiye Elektrik Enerjisi U“" retim Geni,sletme Planlamasında Yenilenebilir

Enerji Kaynaklarının Etkileri, Kocaeli U“" niversitesi Fen Bilimleri En-stitu“su“(2013)

11. U.S. Energy Information Administration : Annual Energy Outlook (2014)

12. How much carbon dioxide is produced when different fuels are burned?, http:

//www.eia.gov/tools/faqs/faq.cfm?id=73\&t=11 2014

13. NOx content of biomass, http://www.ces.ncsu.edu/nreos/forest/feop/ biomass-south/proceedings/pdf/0923-1300-C3-Abrams.pdf

14. Tekiner, H.: Multi-Objective Stochastic Models for Electricity Generation Expan- sion Planning Problems Considering Risk, Graduate School-New Brunswick Rut-gers, The State University of New Jersey (2010)

15. Bertani, R, Thain, T.: Geothermal Power Generating Plant C O2 Emission Survey, International Geothermal Association (2002) 